\section{Pakistan: basic education essential to underpin reforms}

SIR - The overhauling of Pakistan's academic institutions (Nature 461, 11-12 and 38-39; 2009) would have been more effective and sustainable if policy-makers had opted instead for a two-pronged approach, promoting basic education alongside higher education.

Only $56 \%$ of children are enrolled in primary schools in Pakistan, compared with $83 \%$ in India, 94\% in Iran and 98\% in South Korea (see go.nature. com/RtyZks). These figures are lower for secondary schools, but Pakistan's are lowest by far. To increase enrolment in higher education, we have to increase the supply of potential candidates by investing more in primary and secondary schooling.

You mention that candidates for Pakistan's domestic PhD programmes are less well qualified than those going abroad. It is difficult to see how this situation will "correct itself", as your Editorial claims, if "too many ill-prepared students [are] gaining doctorates", as Athar Osama and colleagues suggest in their Opinion article. More than twice as many postgraduates are produced at home as abroad, and these are more likely to stay in the country to become future supervisors, so the cycle of poorly trained researchers is set to continue.

Pakistan's Higher Education Commission has not provided figures for the percentage of candidates who return to the country after studying abroad. If a substantial number decide to stay away, the reforms could backfire and boost the brain drain to developed countries.

Muhammad Naim Siddiqi Department of Psychiatry, Aga Khan University, Stadium Road, Karachi 74800, Pakistan e-mail: naim.siddiqi1@gmail.com

\begin{abstract}
Abdul Wahab Yousafzai Department of Psychiatry, Ayub Medical College, Abbottabad 22010, Pakistan Raza Ur Rahman Department of Psychiatry, Dow University of Health Sciences, Baba-e-Urdu Road, Karachi 74200, Pakistan
\end{abstract}

\section{Pakistan: cash infusion of limited use to universities}

$\mathrm{SIR}$ - Athar Osama and colleagues' Opinion article (Nature 461, 38-39; 2009) aims to provide a factual balance-sheet for Pakistan's higher-education system under General Pervez Musharraf. But several critical omissions leave it less than factual.

For example, the former government wasted enormous sums of money on prestige megaprojects. Nine new universities were abandoned after partial construction because of a lack of trained faculty, and expensive imported scientific equipment remains under-utilized many years later. The claimed $400 \%$ increase in publications was a result of salary bonuses awarded to professors who published in international journals, largely irrespective of substance and quality. These payments fostered a plagiarism culture that still goes unpunished.

The authors draw attention to a large increase in "relative impact" in some disciplines, based on citation of papers published in 2003-07. But were self-citations (a common ploy) eliminated from this count? I used an option available from Thomson Scientific and found the opposite result after eliminating self-citations.

The authors also praise the Higher Education Commission for increasing university professors' salaries. But this has created social disparities - a full professor now earns 20-30 times more than a school teacher. Professors, bent on removing barriers to their promotions and incomes, take on very large numbers of PhD students. To ensure that these students get their degrees, many professors seek the elimination of international testing, hitherto used as a metric for gauging student performance.

Pakistan's failed experiment provides a counter-example to the conventional wisdom that money is the most crucial element in the reform process. An enormous cash infusion has failed to improve teaching and research quality. There is much that other developing countries can learn from our experience sadly, this is not what the authors convey.

Pervez Hoodbhoy Department of Physics, Quaid-e-Azam University, Islamabad 45320, Pakistan e-mail: hoodbhoy@mit.edu

\section{Pakistan: sense of urgency powered education reforms}

SIR - As head of the Higher Education Commission (HEC) in Pakistan in 2003-08, I would like to add some points to those made in the Opinion article by Athar Osama and others on Pakistan's reform experiment in higher education (Nature 461, 38-39; 2009).

We awarded research grants to qualified faculty to develop a high-quality indigenous PhD programme - not to produce “5,000 new PhDs ... over 5 years", as the authors suggest. Measures were introduced to ensure the quality of local PhDs, including mandatory evaluation of theses by at least two professors from technologically advanced countries. Because there were not enough suitable $\mathrm{PhD}$ supervisors in the universities, we sent some 3,800 students abroad, mainly to the United States and Europe, to study for a PhD, at a total cost of about US $\$ 1$ billion.

The work carried out was overseen by an 18-member board that included federal secretaries of science and technology and education, representatives of the four provincial ministries of education, representatives of the senate and eminent private citizens. This board was empowered to change the budgetary allocations as well as the overall directions of the programme.

There followed a huge increase in international scientific research publications, from 600 or so in 2001 to more than 4,200 in 2008 . About 50 new universities and degree-awarding institutes were established during this period, and enrolment in higher education almost tripled to about 400,000 by the end of 2008 , having been just 135,000 in 2003.

A digital library was established to provide free access to 25,000 international journals and 45,000 textbooks for all public-sector university students. In the 2008 Times Higher Education rankings, four Pakistani universities are among the top 600 in the world - an unattainable position before 2003.

Our accounts were audited by government auditors and by an international private auditing company (we were the only government organization to employ one) to ensure transparency in expenditure.

We do not agree with the authors' view that we acted in too much of a hurry. We did implement the programmes with a certain sense of urgency, but that had nothing to do with the transient nature of the Musharraf government. It was due to our eagerness to get on with things and to avoid bureaucratic hurdles. They were a breathless six years, but all rules were strictly observed and no shortcuts were taken in achieving the huge positive changes that took place.

Atta-ur-Rahman COMSTECH Secretariat, 33 Constitution Avenue, G-5/2, Islamabad 44000, Pakistan e-mail: aurahman786@gmail.com 